Pesq. Vet. Bras. 29(7):487-497, julho 2009

\title{
Polioencefalomalacia em bovinos: epidemiologia, sinais clínicos e distribuição das lesões no encéfalo ${ }^{1}$
}

\begin{abstract}
Fabiano J.F. de Sant'Ana², Daniel R. Rissi², Ricardo B. de Lucena ${ }^{2}$, Ricardo A.A. Lemos ${ }^{3}$, Ana Paula A. Nogueira ${ }^{4}$ e Claudio S.L. Barros ${ }^{5 *}$

ABSTRACT.- Sant'Ana F.J.F., Rissi D.R., Lucena R.B., Lemos R.A.A., Nogueira A.P.A. \& Barros C.S.L. 2009. [Bovine polioencephalomalacia: Epidemiology, clinical signs and distribution of lesions in the brain.] Polioencefalomalacia em bovinos: epidemiologia, sinais clínicos e distribuição das lesões no encéfalo. Pesquisa Veterinária Brasileira 29(7):487-497. Departamento de Patologia, Universidade Federal de Santa Maria, 97105-900, Santa Maria, RS, Brazil. E-mail: claudioslbarros@uol.com.br

Thirty one cases of polioencephalomalacia (PEM) diagnosed from 1999-2008 in cattle from the Southern (13 cases) and Midwestern (18 cases) Brazil were studied. Morbidity (0.04\%-6.66 \%), mortality (0.04\%-6.66 \%), and lethality (50\%-100\%) rates were similar in both regions studied. There was no clear association between PEM cases and age, sex or seasonality. Cases occurred mainly in cattle raised at pasture; in the Southern the disease affected mainly young cattle (one-year old or less) while mainly older cattle (three-year-old or older) were affected in the Midwest. Clinical signs more frequently observed included blindness, incoordination, circling, opisthotonus, recumbence and peddling movements. Clinical course varied from 12 hours to 8 days (average three days and a half). In 11 cases no gross changes were observed in the brain. Main gross findings in the brain of remaining cases included congestion with swelling and flattening of gyri, softening and yellow discoloration of cerebral cortex, hemorrhagic foci in the brain stem, cerebellum and telencephalon, and cerebellar herniation. The main histopathological changes were in the cortex of occipital, parietal and frontal telencephalic lobes; however less prominent and less frequently found lesions occurred in the hippocampus, basal nuclei, thalamus, midbrain, and cerebellum. The type of microscopic cortical lesions was consistent in all cases and included segmentar laminar neuronal necrosis (red neurons), spongiosis, swollen of vascular endothelial nuclei, Alzheimer type II astrocytes and infiltration of gitter cells. In $20 \%$ of the cases there was mild lymphohistiocytic cellular infiltrate and in $13 \%$ of the cases there was mild infiltrate by neutrophils and eosinophils. Additionally, mild to moderate necrohemorrhagic lesions were observed in $49 \%$ of the cases in the basal nuclei, in $39 \%$ of the cases in brain stem and in $26 \%$ of the cases in the thalamus. Brain lesions were consistently found in the cortical laminae of the occipital, parietal and frontal telencephalic lobes. In such locations, most frequently affected cortical layers both by neuronal necrosis and edema were external and internal granular layers. Both gyri and sulci were equally affected.
\end{abstract}

INDEX TERMS: Diseases of cattle, neuropathology, distribution of lesions, polioencephalomalacia.

\footnotetext{
${ }^{1}$ Recebido em 20 de janeiro de 2009.

Aceito para publicação em 11 de fevereiro de 2009.

Parte da tese de Doutorado do primeiro autor. Financiado integralmente pelo Grant de Pesquisador 1-A do CNPq (Proc. 307876/20063).

${ }^{2}$ Programa de Pós-Graduação em Medicina Veterinária, área de concentração em Patologia Veterinária, Centro de Ciências Rurais, Universidade Federal de Santa Maria (UFSM), Santa Maria, RS 97105-900, Brasil. Bolsista do CNPq.
}

\footnotetext{
${ }^{3}$ Departamento de Medicina Veterinária, Faculdade de Medicina Veterinária e Zootecnia (FMVZ), Universidade Federal de Mato Grosso do Sul (UFMS), Av. Felinto Miller s/n, Cidade Universitária, Campo Grande, MS 79070-900, Brasil.

${ }^{4}$ Programa de Pós-Graduação em Ciência Animal, FMVZ, UFMS, Campo Grande, MS.

${ }^{5}$ Departamento de Patologia, UFSM, Santa Maria, RS 97105-900. *Pesquisador 1-A do CNPq (Proc.307876/2006-3) e autor para correspondência: claudioslbarros@uol.com.br
} 
RESUMO.- Trinta e um casos de polioencefalomalacia (PEM) diagnosticados de 1999-2008 em bovinos do Sul (13 casos) e Centro-Oeste (18 casos) brasileiros foram estudados. As taxas de morbidade (0,04\%-6,66 \%), mortalidade $(0,04 \%-6,66 \%)$ e letalidade $(50 \%-100 \%)$ foram semelhantes em ambas as regiões estudadas. Não houve uma associação clara entre os casos de PEM e a idade, sexo dos bovinos e sazonalidade. Os casos ocorreram principalmente em bovinos criados de forma extensiva em pastagem. Na Região Sul a doença afetou principalmente bovinos jovens (um ano de idade ou menos), enquanto que principalmente bovinos mais velhos ( 3 anos de idade ou mais) foram afetados no Centro-Oeste. Os sinais clínicos mais frequentemente observados incluíram cegueira, incoordenação, andar em círculos, opistótono, decúbito e movimentos de pedalagem. A evolução do quadro clínico variou de 12 horas a 8 dias (media 3 dias e meio). Em 11 encéfalos não foram observadas alterações macroscópicas; as principais alterações macroscópicas nos outros casos incluíam congestão com tumefação e achatamento das circunvoluções, amolecimento e amarelamento do córtex telencefálico, focos de hemorragia no tronco encefálico, cerebelo e telencéfalo e herniação cerebelar. As principais alterações histológicas ocorreram no córtex dos lobos telencefálicos occipital, parietal e frontal; no entanto, lesões menos acentuadas e menos frequentemente observadas ocorreram no hipocampo, núcleos da base, tálamo, mesencéfalo e cerebelo. O tipo de lesão microscópica cortical era consistente em todos os casos e incluía necrose neuronal (neurônio vermelho) laminar segmentar, espongiose, tumefação do núcleo das células endoteliais, astrócitos Alzheimer tipo II e infiltração por células gitter. Em $20 \%$ dos casos havia um leve infiltrado celular linfo-histiocitário e em 13\% dos casos havia leve infiltrado de neutrófilos e eosinófilos. Adicionalmente, lesões necro-hemorrágicas leves ou moderadas foram observadas em $49 \%$ dos casos nos núcleos da base, em $39 \%$ dos casos no tronco encefálico e em $26 \%$ dos casos no tálamo. Lesões telencefálicas foram consistentemente observadas nas lâminas dos córtices dos lobos occipital, parietal e frontal. Nessas regiões as camadas granular externa e interna foram as mais afetadas tanto por neurônios necróticos quanto por edema em todas as regiões avaliadas. Tanto os giros quanto os sulcos foram afetados igualmente.

TERMOS DE INDEXAÇÃO: Doenças de bovinos, neuropatologia, distribuição de lesões, polioencefalomalacia.

\section{INTRODUÇÃO}

Polioencefalomalacia (PEM) é um diagnostico morfológico para necrose com amolecimento (malacia) da substância cinzenta (polio) do encéfalo. No entanto, em 1956, no Colorado, EUA, o termo PEM foi empregado para designar não somente urna lesão, mas uma doença específica de ruminantes, presumivelmente causada por deficiência de tiamina e caracterizada por necrose do córtex telencefálico (Jensen et al. 1956), e tem sido usado desde então como sinônimo dessa condição em ruminantes. A denominação necrose cerebrocortical é usada para designar a mesma condição na Europa (Markson et al. 1972, Edwin et al. 1979, Jeffrey et al. 1994).

A partir da década de 70 do século passado, muitos pesquisadores observaram que a PEM em ruminantes pode ter outras causas, incluindo intoxicação por enxofre (Gould 1998, 2000, Loneragan et al. 1998, Kul et al. 2006), intoxicação por sal associada à privação de água (Lindley 1977, Trueman \& Clague 1978, Scarratt et al. 1985), intoxicação por chumbo (Christian \& Tryphonas 1971, Priester \& Hayes 1974, Lemos et al. 2004, Traverso et al. 2004, Krametter-Froetscher et al. 2007), administração de determinados anti-helmínticos, como levamisole e tiabendazole (Linklater et al. 1977), administração de análogos da tiamina, como o amprólio (Loew \& Dunlop 1972, Markson et al. 1974, Morgan 1974), ingestão de cadáveres (Purisco 1982), ingestão de melaço - provavelmente associada à intoxicação por enxofre - (Mella et al. 1976), mudança brusca de pastos ruins para outros de ótima qualidade (Moro et al. 1994), ingestão de plantas ricas em tiaminases (Pritchard \& Eggleston 1978, Ramos et al. 2005), forma aguda da intoxicação por Phalaris spp. (Anderton et al. 1994) e infecção por herpesvírus bovino (Carrillo et al. 1983a,b). Em algumas dessas situações, a participação da tiamina na patogênese da PEM foi questionada, uma vez que não havia alterações nas concentrações sanguíneas dessa substância.

No Brasil, a PEM tem sido descrita em bovinos, ovinos, bubalinos e caprinos (Colodel et al. 1998, Nascimento et al. 2003, Lemos 2005, Lima et al. 2005, Lemos \& RietCorrea 2007, Guimarães et al. 2008). Em bovinos são descritos surtos da doença nos estados do Rio Grande do Sul (Santos et al. 1983, Riet-Correa et al. 1998, Motta et al. 1999, Sanches et al. 2000, Traverso et al. 2001, Schild et al. 2005), Minas Gerais (Ferreira et al. 1986, Moro et al. 1994), Pernambuco (Vieira et al. 2007), Mato Grosso do Sul, São Paulo (Purisco 1982, Nakazato et al. 2000, Gonçalves et al. 2001, Lemos 2005, David et al. 2007), Mato Grosso e Goiás (Grecco et al. 2001, Lemos 2005).

O objetivo desse trabalho é descrever os achados epidemiológicos, clinicopatológicos e a distribuição das alterações no encéfalo de 31 casos naturais de polioencefalomalacia em bovinos do Rio Grande do Sul e do CentroOeste brasileiro.

\section{MATERIAL E MÉTODOS}

Foram estudados 31 casos de polioencefalomalacia diagnosticados em bovinos de 1999-2008 no Laboratório de Patologia Veterinária (LPV) da Universidade Federal de Santa Maria (UFSM) e no Laboratório de Anatomia Patológica (LAP) da Universidade Federal de Mato Grosso do Sul (UFMS). Treze casos eram oriundos do Rio Grande do Sul (Quadro 1) e 18 casos do Centro-Oeste brasileiro (Quadro 2).

Para a caracterização do tipo, intensidade e distribuição das lesões no encéfalo desses 31 bovinos, os cérebros foram coletados inteiros e fixados em formol a $10 \%$. Fragmentos adi- 
Quadro 1. Dados epidemiológicos de 13 casos de polioencefalomalacia diagnosticados em bovinos no Rio Grande do Sul

\begin{tabular}{|c|c|c|c|c|c|c|c|c|c|}
\hline Caso & Município & Raça & Idade & Sexo & $\begin{array}{l}\text { Época do } \\
\text { diagnóstico }\end{array}$ & $\begin{array}{l}\text { Bovinos } \\
\text { sob risco }\end{array}$ & $\begin{array}{l}\text { Bovinos } \\
\text { afetados }\end{array}$ & $\begin{array}{l}\text { Bovinos } \\
\text { mortos }\end{array}$ & $\begin{array}{l}\text { Duração do } \\
\text { curso clínico }\end{array}$ \\
\hline$V-0425-02$ & Val de Serra & $\mathrm{SRD}^{\mathrm{a}}$ & 1 ano & Macho & Setembro/2002 & n.i. ${ }^{b}$ & n.i. & 2 & 8 dias \\
\hline V-0433-02 & Val de Serra & SRD & 1 ano & Macho & Setembro/2002 & n.i. & n.i. & 2 & 2 dias \\
\hline V-0122-04 & Cacequi & Red Angus & 5 meses & Fêmea & Fevereiro/2004 & 150 & 8 & 4 & 5 dias \\
\hline Vn-341-04 & Agudo & SRD & 7 meses & Fêmea & Outubro/2004 & n.i. & n.i. & 1 & 5 dias \\
\hline Vn-158-05 & Santa Maria & SRD & 2 anos & Macho & Maio/2005 & n.i. & n.i. & n.i. & n.i. \\
\hline V-0926-06 & Silveira Martins & SRD & $11 / 2$ ano & Macho & Setembro/2006 & 15 & 1 & 1 & 3 dias \\
\hline V-1003-07 & Pinhal Grande & SRD & 2 anos & Macho & Agosto/2007 & 30 & 1 & 1 & 4 dias \\
\hline$V-1100-07$ & São Pedro do Sul & Zebuíno & 1 ano & Macho & Outubro/2007 & 400 & 1 & 1 & 8 dias \\
\hline Vn-086-08 & Nova Palma & SRD & 80 dias & Macho & Março/2008 & n.i. & 11 & 11 & 2 dias \\
\hline V-0808-08 & Júlio de Castilhos & SRD & 3 anos & Macho & Agosto/2008 & 800 & 1 & 1 & n.i. \\
\hline V-0904-08 & Maçambará & Angus & 10 meses & Fêmea & Setembro/2008 & 800 & 2 & 2 & 2 dias \\
\hline V-0935-08 & Ibiraiaras & Zebuíno & 6 meses & Fêmea & Setembro/2008 & n.i. & 2 & 2 & 2 dias \\
\hline V-0967-08 & Maçambará & Angus & 8 meses & Macho & Outubro/2008 & 800 & 2 & 2 & 2 dias \\
\hline
\end{tabular}

$\overline{\mathrm{a} S R D}=$ sem raça definida, ${ }^{\mathrm{b}}$ n.i. $=$ não informado.

Quadro 2. Dados epidemiológicos de 18 casos de polioencefalomalacia diagnosticados em bovinos do CentroOeste brasileiro

\begin{tabular}{|c|c|c|c|c|c|c|c|c|c|}
\hline Caso & Município & Raça & Idade & Sexo & $\begin{array}{c}\text { Época do } \\
\text { diagnóstico }\end{array}$ & $\begin{array}{l}\text { Bovinos } \\
\text { sob risco }\end{array}$ & $\begin{array}{l}\text { Bovinos } \\
\text { afetados }\end{array}$ & $\begin{array}{l}\text { Bovinos } \\
\text { mortos }\end{array}$ & $\begin{array}{l}\text { Duração do } \\
\text { curso clínico }\end{array}$ \\
\hline 9644 & Bandeirantes $^{a}$ & $\mathrm{SRD}^{\mathrm{b}}$ & 2 anos & Macho & Janeiro/1999 & 2.000 & 3 & 2 & 3 dias \\
\hline 10248 & Campo Grande ${ }^{a}$ & Nelore & $11 / 2$ ano & Macho & Janeiro/2000 & 350 & 2 & 2 & 4 dias \\
\hline 11655 & Porto Murtinhoa & Nelore & 2 anos & Macho & Março/2002 & 30.000 & 12 & 12 & n.i. ${ }^{\mathrm{C}}$ \\
\hline 11656 & Coxima & Nelore & $11 / 2$ ano & Fêmea & Março/2002 & 1.000 & 2 & 1 & n.i. \\
\hline 11937 & Pedra Pretad & Nelore & 5 anos & Fêmea & Julho/2002 & n.i. & 1 & 1 & n.i. \\
\hline 12709 & Anastácioa & Nelore & 5 anos & Fêmea & Maio/2003 & 500 & 1 & 1 & n.i. \\
\hline 13790 & Rosário Oeste & Nelore & 2 anos & Fêmea & Maio/2004 & 218 & 1 & 1 & 2 dias \\
\hline 13894 & Costa Rica ${ }^{a}$ & Nelore & 1 ano & Fêmea & Julho/2004 & n.i. & n.i. & n.i. & 3 dias \\
\hline 14105 & Barra dos Garças $^{d}$ & Nelore & 6 anos & Fêmea & Setembro/2004 & n.i. & n.i. & n.i. & 5 dias \\
\hline 14282 & Itumbiara ${ }^{\mathrm{e}}$ & SRD & $21 / 2$ anos & n.i. & Janeiro/2005 & n.i. & n.i. & n.i. & n.i. \\
\hline 14454 & Torixoréu ${ }^{d}$ & Nelore & 5 anos & Fêmea & Abril/2005 & n.i. & n.i. & n.i. & n.i. \\
\hline 14498 & Camapuãa & Nelore & 3 anos & Macho & Abril/2005 & n.i. & 2 & 1 & 4 dias \\
\hline V-0239-05 & Silvânia ${ }^{e}$ & SRD & 8 anos & n.i. & Agosto/2005 & n.i. & n.i. & n.i. & 12 horas \\
\hline 14844 & Sidrolândiaa & Charolês & $11 / 2$ ano & Fêmea & Novembro/2005 & n.i. & 2 & 2 & n.i. \\
\hline 14932 & Terenos $^{a}$ & Nelore & $31 / 2$ anos & Macho & Fevereiro/2006 & n.i. & n.i. & n.i. & 2 dias \\
\hline 15744 & Terenos $^{a}$ & Nelore & 5 anos & Fêmea & Fevereiro/2008 & n.i. & n.i. & n.i. & n.i. \\
\hline 15795 & Tacuru ${ }^{\mathrm{a}}$ & SRD & $11 / 2$ ano & Fêmea & Março/2008 & 1.850 & 50 & 30 & n.i. \\
\hline 15931 & Terenos $^{a}$ & SRD & Adulto & Macho & Agosto/2008 & 1.200 & 2 & 1 & n.i. \\
\hline
\end{tabular}

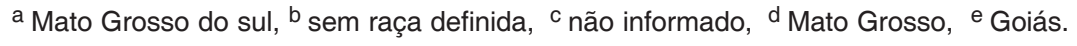

cionais não-fixados de tálamo, cerebelo, medula espinhal cervical, bulbo olfatório e de córtex frontal foram testados por imunofluorescência direta para raiva e submetidos à cultura celular para diagnóstico de infecção por herpesvírus bovino (BoHV). Adicionalmente foi colhido e fixado em formol, o complexo gânglio de Gasser, rete mirabile carotídea e hipófise $(\mathrm{GRH})$. Após a fixação, foram realizados cortes transversais no encéfalo com intervalos de 1-2cm para avaliação macroscópica. As seguintes seções foram preparadas para avaliação microscópica: cerebelo, bulbo na altura do óbex, ponte com pedúnculos cerebelares, mesencéfalo na altura dos colículos rostrais, tálamo, núcleos basais e hipocampo; foram também examinados os lados direito e esquerdo do telencéfalo frontal, parietal e occipital. Adicionalmente, o exame histológico foi realizado em um monobloco do complexo GRH. Todos os fragmentos foram processados rotineiramente para histologia, incluídos em parafina e corados pela hematoxilina-eosina.

As alterações observadas no encéfalo foram graduadas de acordo com a intensidade numa escala de 0 (ausência de le- são) a 3 (lesão acentuada). Cada lesão tinha seu grau aferido de acordo com a média de percepção subjetiva de três patologistas que examinaram todos os casos. Foram avaliados o grau de intensidade e a distribuição nos diferentes locais examinados das seguintes alterações histológicas: gliose focal, gliose difusa, tumefação de núcleos de células endoteliais, separação entre as substâncias cinzenta e branca, edema de neurópilo, congestão, hemorragia, necrose neuronal (caracterizada por picnose nuclear e eosinofilia e encarquilhamento citoplasmáticos), neuronofagia, malacia (o termo malacia foi empregado aqui significando necrose de todas as células neuroectodérmicas com manutenção das células mesenquimais (i.é, células gitter, células endoteliais) que sobrevivem e participam do processo [Innes \& Saunders 1962]), lesão residual (estrutura cavitária formada por pequenos vasos e numerosas células gitter remanescentes) e infiltrado inflamatório perivascular e/ou meníngeo. A distribuição do edema e da necrose neuronal (neurônio vermelho) nas lâminas da substância cinzenta do telencéfalo foi também determinada. Os critérios para inclusão 
de casos neste estudo foram: 1) casos em que havia necrose do córtex telencefálico 2) mas, sem lesões inflamatórias acentuadas e 3) que apresentaram respectivamente imunofluorescência direta e isolamento viral negativos para raiva e BoHV.

\section{RESULTADOS}

Os principais dados epidemiológicos dos casos de PEM observados no Rio Grande do Sul (RS) e Centro-Oeste encontram-se respectivamente nos Quadros 1 e 2. A maioria $(9 / 13$ ou $70 \%)$ dos casos diagnosticados no RS ocorreu em bovinos de um ano de idade ou menos, enquanto no Centro-Oeste, metade dos casos (9/18) ocorreu em bovinos com idade superior ou igual a três anos, e apenas cinco bovinos (27\%) tinham menos de um ano e meio de idade. Não se observou sazonalidade na ocorrência da doença nas duas regiões geográficas estudadas.

Os coeficientes de morbidade $(0,04 \%-6,66 \%)$, mortalidade $(0,04 \%-6,66 \%)$, e letalidade $(50 \%-100 \%)$ foram semelhantes nas duas regiões estudadas. Na maioria das propriedades onde ocorreram os casos, a letalidade foi de $100 \%$. Em dois casos de uma mesma propriedade no RS (V-0904-08 e V-0967-08, Quadro 1), a criação era semi-intensiva com a alimentação dos bovinos complementada com feno e ração. Em todas as outras propriedades das duas regiões estudadas, o sistema de criação era extensivo, com os bovinos no pasto. Em dois casos do Centro-Oeste (10248, 11656, Quadro 2) e em um do RS (V-1003-07, Quadro 1), havia informação no histórico de transferência recente de bovinos entre propriedades. Um bovino do RS (V-1003-07, Quadro 1) apresentou PEM após ser colocado em um pasto adubado com uréia há 20 dias. Um outro bovino da região Centro-Oeste (9644, Quadro 2) pertencia a um rebanho que estava no pasto de Brachiaria decumbens e recebia sal protéico, probiótico e $800 \mathrm{~g}$ de milho/dia/bovino.

O Quadro 3 mostra a frequência de sinais clínicos descritos em 30 casos de PEM. Os principais sinais observados foram cegueira, incoordenação, andar em círculos, opistótono, decúbito e movimentos de pedalagem. Em um caso da região Centro-Oeste (V-0239-05, Quadro 2) os sinais clínicos não foram informados. A duração dos sinais clínicos variou de 12 horas a oito dias (média de três dias e meio); no entanto, essa informação não estava disponível em 12 casos. Os Bovinos 14498 e 15744 (Quadro 2) do Centro-Oeste foram tratados com tiamina, porém morreram alguns dias após o tratamento. Na propriedade do Bovino 14498 (Quadro 2), um outro bovino apresentou os mesmos sinais clínicos, foi tratado com tiamina e corticosteróides e se recuperou.

Os principais achados descritos no encéfalo consistiam de congestão e tumefação com achatamento das circunvoluções cerebrais (Fig.1). Em alguns casos, havia áreas multifocais amolecidas e amareladas. Adicionalmente, focos de hemorragia foram visualizados em quatro casos no tronco encefálico, cerebelo ou telencéfalo. Em três casos foi anotada a observação de deslocamento
Quadro 3. Frequência de sinais clínicos em 30 casos de polioencefalomalacia em bovinos diagnosticados no Rio Grande do Sul e Centro-Oeste brasileiro

\begin{tabular}{lc}
\hline Sinais clínicos & Frequência \\
\hline Incoordenação & $17(57 \%)$ \\
Decúbito & $17(57 \%)$ \\
Cegueira & $14(47 \%)$ \\
Opistótono & $11(37 \%)$ \\
Movimentos de pedalagem & $6(20 \%)$ \\
Andar em círculos & $5(17 \%)$ \\
Ataxia & $3(10 \%)$ \\
Quedas frequentes & $3(10 \%)$ \\
Bruxismo & $3(10 \%)$ \\
Sialorréia & $3(10 \%)$ \\
Nistagmo & $3(10 \%)$ \\
Depressão & $2(6,7 \%)$ \\
Afastamento do rebanho & $2(6,7 \%)$ \\
Convulsões & $2(6,7 \%)$ \\
Emagrecimento progressivo & $2(6,7 \%)$ \\
Apatia & $2(6,7 \%)$ \\
Desidratação & $2(6,7 \%)$ \\
Secreção nasal & $2(6,7 \%)$ \\
Ausência de reflexo de ameaça & $2(6,7 \%)$ \\
Paralisia flácida dos membros pélvicos & $2(6,7 \%)$ \\
Tetania & $2(6,7 \%)$ \\
Agressividade & $2(6,7 \%)$ \\
Miose & $1(3,3 \%)$ \\
Anorexia & $1(3,3 \%)$ \\
Fezes ressecadas & $1(3,3 \%)$ \\
Estrabismo & $1(3,3 \%)$ \\
Diminuição de tônus da língua & $1(3,3 \%)$ \\
Paralisia da cauda & $1(3,3 \%)$ \\
Prostração & $1(3,3 \%)$ \\
Balanços da cabeça & $1(3,3 \%)$ \\
Hiperexcitabilidade & $1(3,3 \%)$ \\
Rigidez dos membros pélvicos & $1(3,3 \%)$ \\
Diarréia & $1(3,3 \%)$ \\
Fraqueza & $1(3,3 \%)$ \\
Anúria & $1(3,3 \%)$ \\
Febre & $1(3,3 \%)$ \\
Conjuntivite & $1(3,3 \%)$ \\
&
\end{tabular}

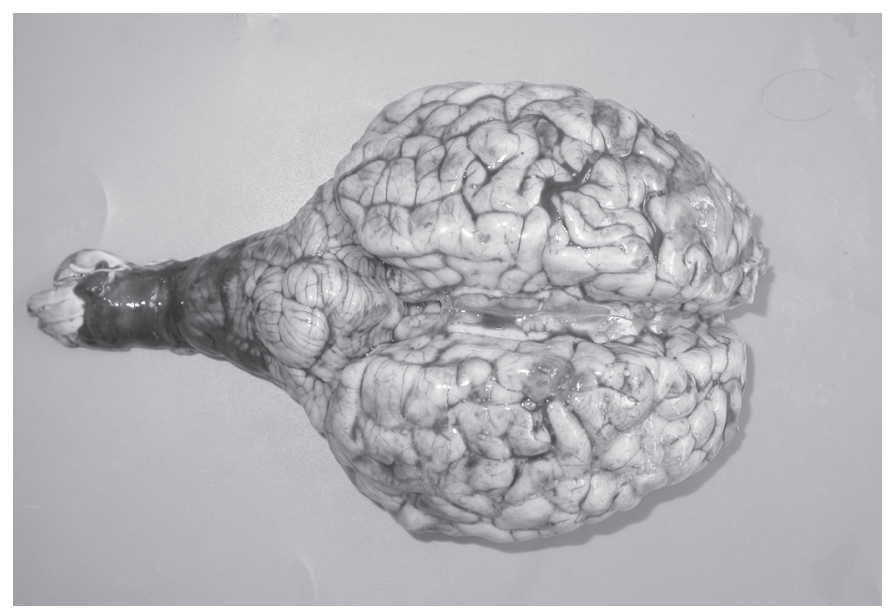

Fig.1. Encéfalo do Bovino Vn-086-08 afetado por polioencefalomalacia. $O$ encéfalo está tumefeito, tem as circunvoluções telencefálicas achatadas, e o verme cerebelar está prolapsado e hemorrágico. 


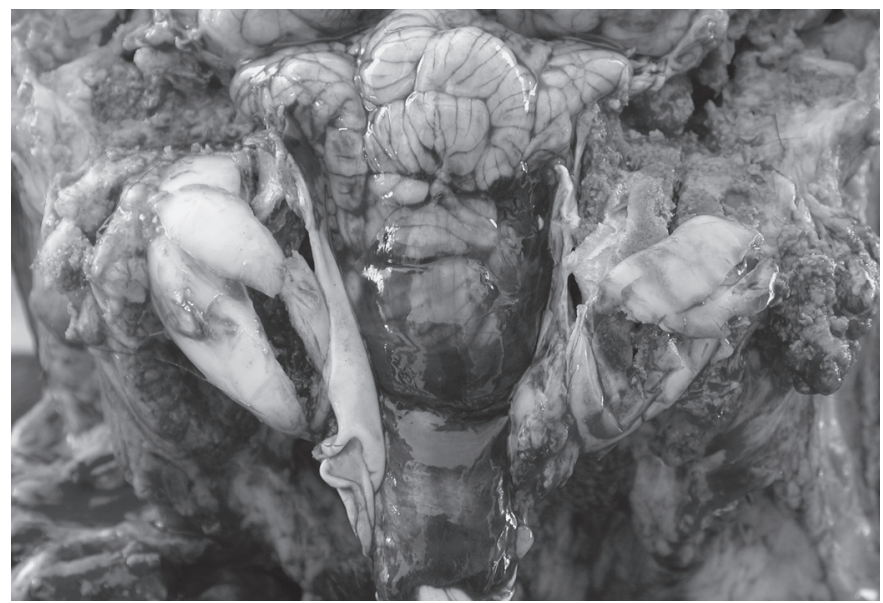

Fig.2. Herniação do cerebelo pelo forame magno e hemorragia subpial no Bovino Vn-086-08 afetado por polioencefalomalacia.

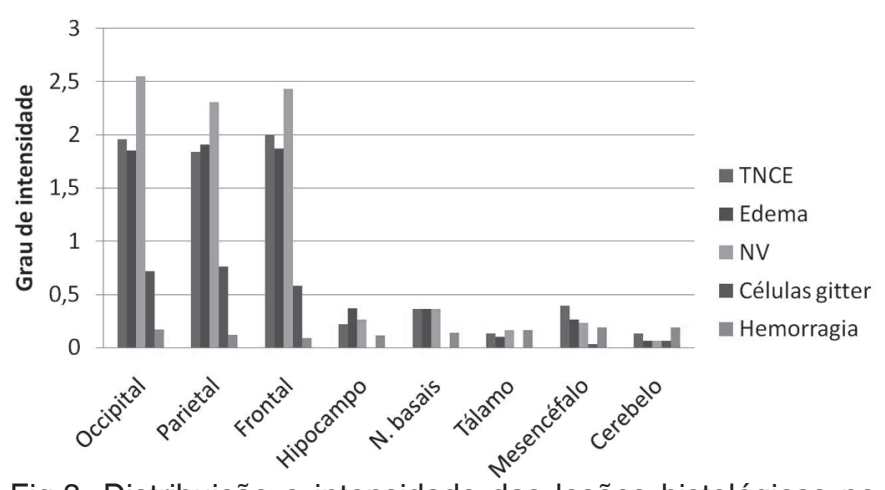

Fig.3. Distribuição e intensidade das lesões histológicas no encéfalo em 31 casos de polioencefalomalacia em bovinos. Graus de intensidade de 0 (ausência de lesão) a 3 (lesão acentuada) foram atribuídos. TNCE = tumefação de núcleos de células endoteliais; NV = neurônios vermelhos (necrose neuronal), N.Basais $=$ núcleos basais.

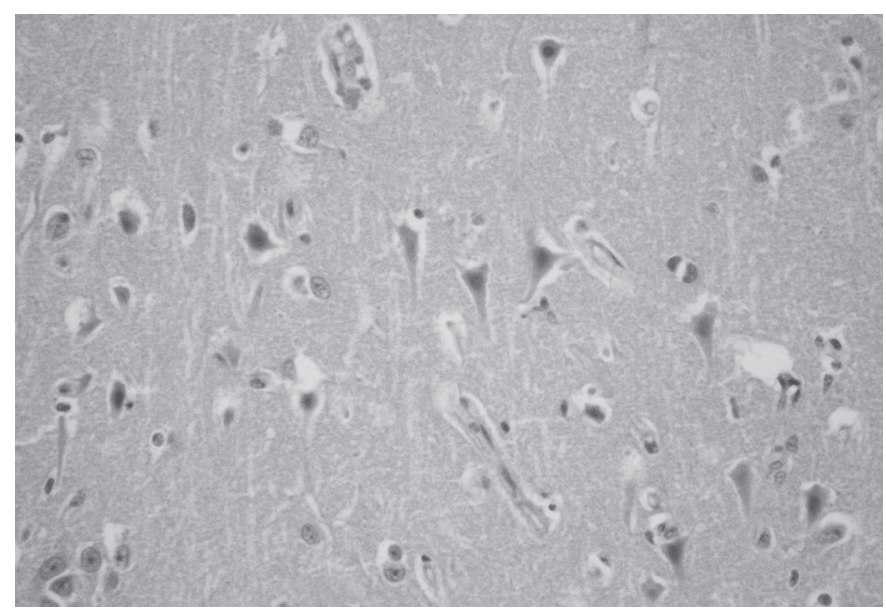

Fig.4. Aspecto histológico do córtex telencefálico do lobo parietal do Bovino V-1003-07 mostrando necrose neuronal laminar. O citoplasma dos neurônios necróticos está encarquilhado e fortemente eosinofílico (neurônios vermelhos); há picnose nuclear e o nucléolo não é mais visualizado. HE, obj.40x.
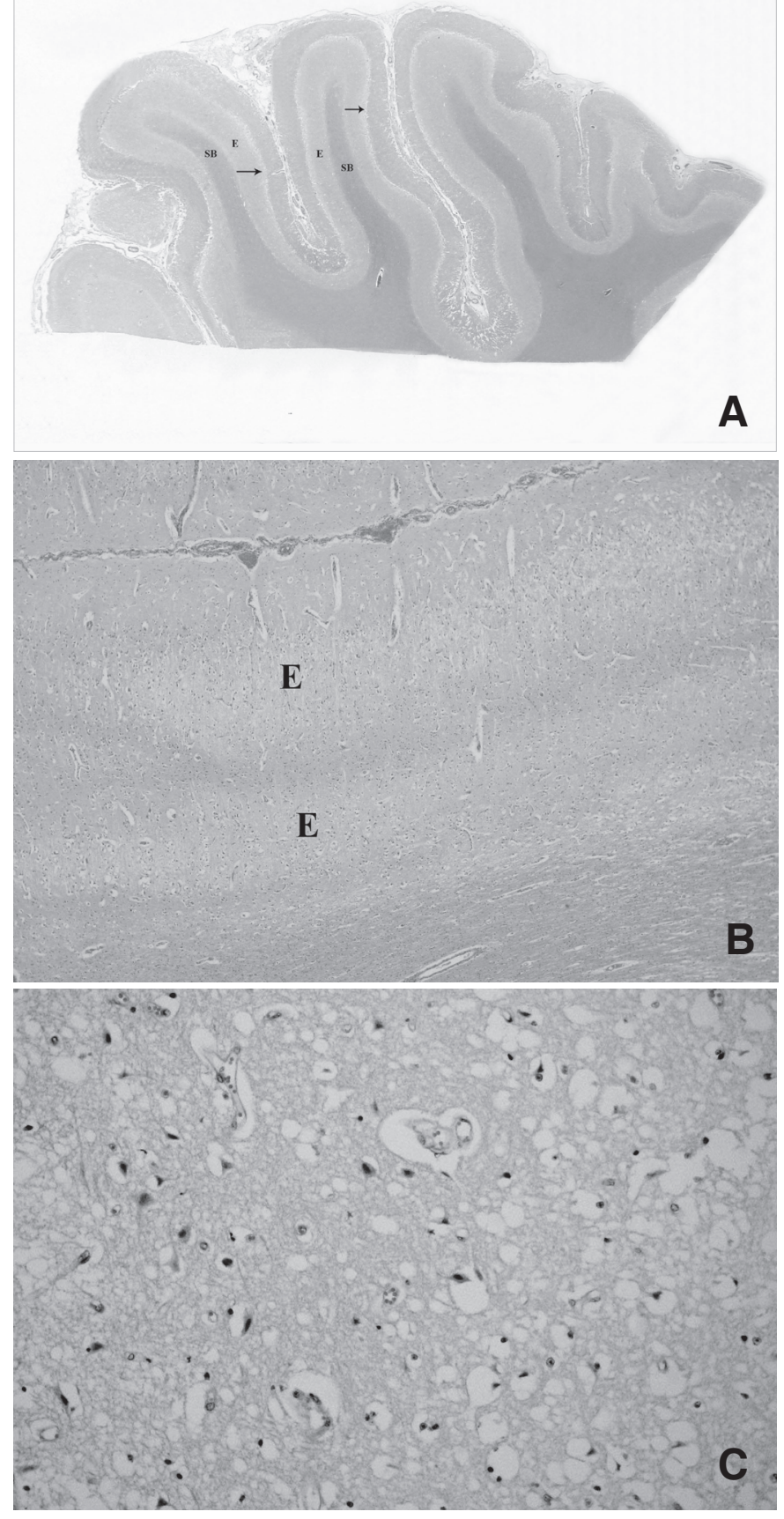

Fig.5. Aspecto histológico do edema do córtex telencefálico. (A) Bovino V-1100-07. O edema (E) aparece como uma linha clara (espongiose) na parte mais profunda do córtex. Uma clivagem (seta) entre a parte mais superficial do córtex e a porção edemaciada é evidente. SB = substância branca. HE, obj.2,5x. (B) Bovino 15931. O edema (E) aparece como duas faixas claras no córtex telencefálico. Os espaços claros ao redor de neurônios e vasos dá o aspecto conhecido como espongiose. HE, obj.10x. (C). Bovino 15744. Observe a distensão dos espaços perineuronais e perivasculares. Os neurônios apresentam necrose neuronal semeIhante à mostrada na Figura 4. HE, obj.40x. 
caudal do cerebelo em direção ao forame magno (herniação cerebelar) (Fig.2). Em 11 dos 31 casos (35\%) não foram observadas alterações macroscópicas.

A Fig. 3 mostra que as principais alterações microscópicas predominaram no córtex occipital, parietal e frontal, mas em muitos casos lesões menos acentuadas também foram detectadas no hipocampo, núcleos basais, tálamo, mesencéfalo e cerebelo. A distribuição das lesões não variou entre os casos do RS e do Centro-Oeste. Em nenhum dos casos foram observadas alterações histológicas no bulbo, na ponte e no complexo GRH. As principais alterações microscópicas no córtex dos hemisférios telencefálico direito e esquerdo foram consistentes em todos os casos e incluíam de necrose neuronal segmentar e laminar (Fig.4), edema (espongiose) perineuronal, perivascular e no neurópilo (Fig.5), tumefação de núcleos de células endoteliais dos vasos (Fig.6) e hipertrofia de astrócitos; ocasionalmente eram observados grupos de

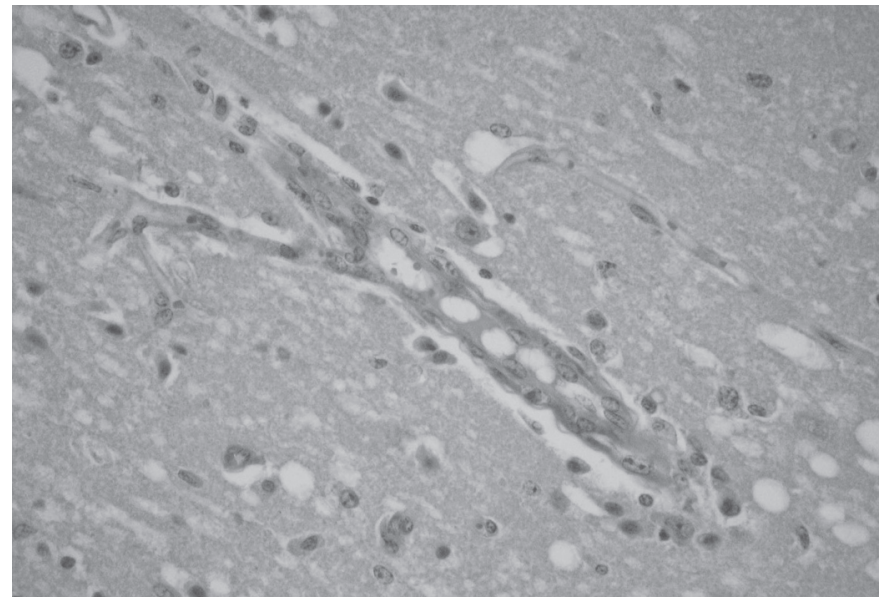

Fig.6. Vaso do córtex telencefálico do Bovino 14454, mostrando tumefação do núcleo das células endoteliais. Os neurônios adjacentes ao vaso estão necróticos. HE, obj.40x.

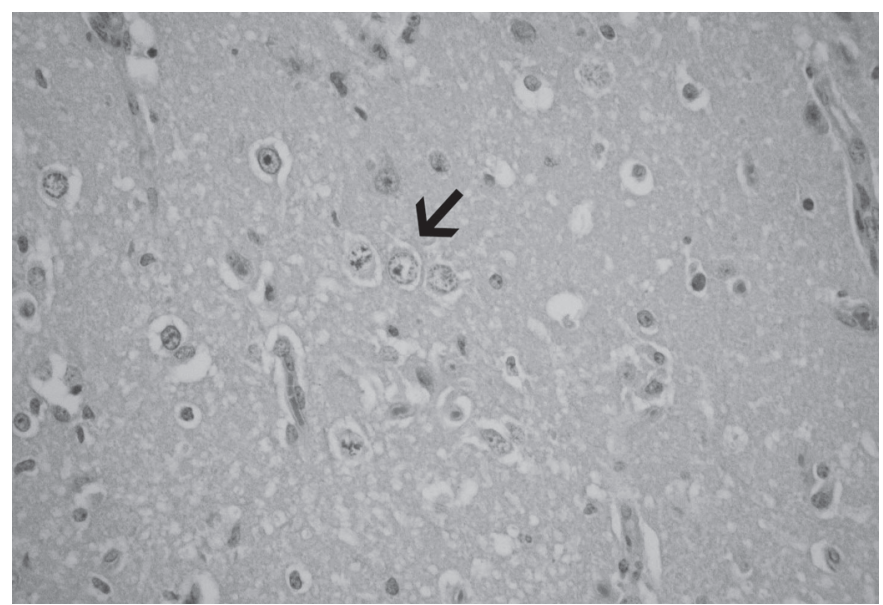

Fig.7. Hipertrofia de astrócitos no córtex telencefálico do Bovino 14454; observe grupos de astrócitos (seta) com núcleos vesiculosos e tumefeitos. Essa morfologia é compatível com a de astrócitos Alzheimer tipo II. HE, obj.40x.
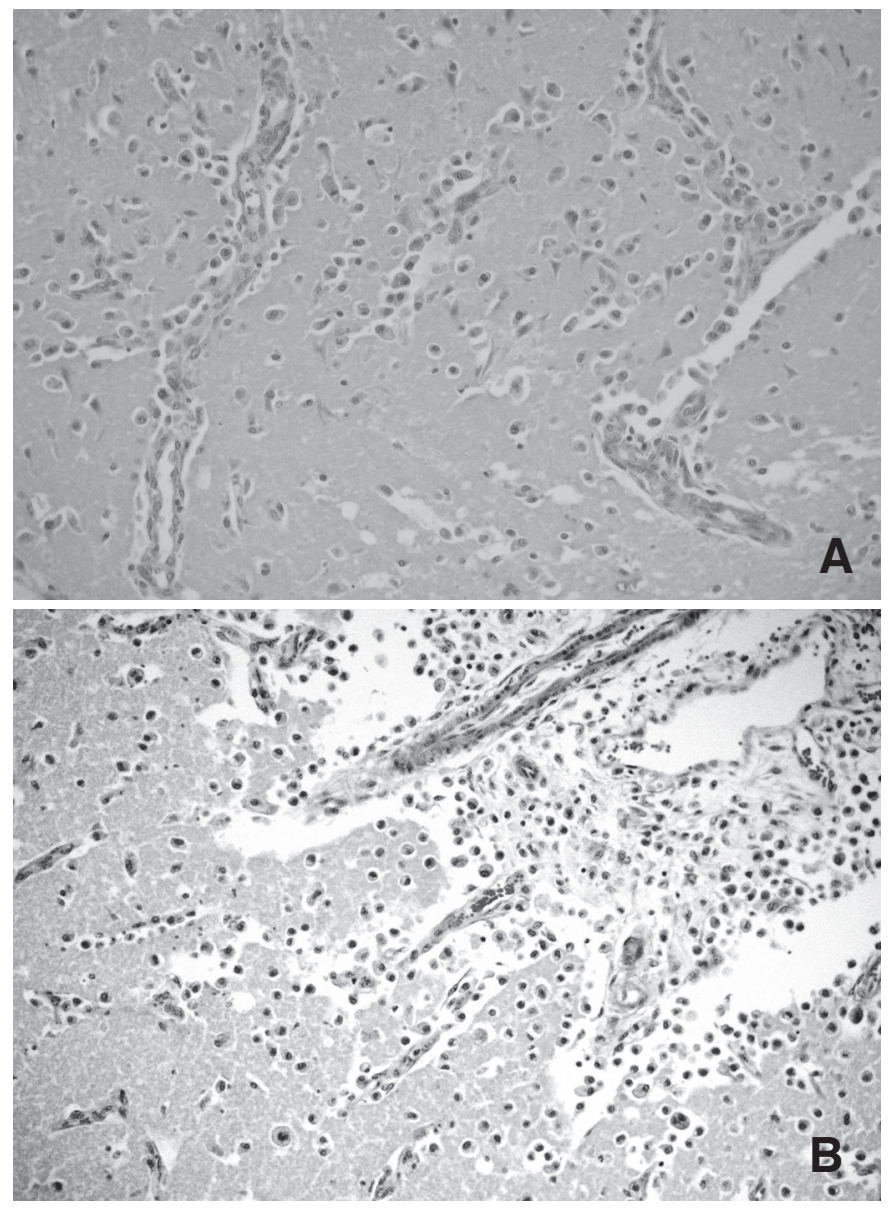

Fig.8. Infiltração de macrófagos espumosos (células Gitter) no encéfalo do Bovino 14454; (A) Essas células podem ser vistas aqui nos espaços perivasculares do córtex e no neurópilo. HE, obj.40x. (B) Células Gitter sob a leptomeninge do córtex occipital. HE, obj.40x.

dois ou três astrócitos com núcleos vesiculosos e tumefeitos, morfologia compatível com astrócitos Alzheimer tipo II (Fig.7); nos casos com lesões mais avançadas, numerosos macrófagos tumefeitos com citoplasma espumoso (células gitter) eram observados principalmente no espaço perivascular e neurópilo do córtex (Fig.8A) e sob as leptomeninges (Fig.8B). Os neurônios necróticos eram caracterizados por encarquilhamento e hipereosinofilia citoplasmáticas, picnose nuclear sem evidenciação nucleolar e desaparecimento da substância de Nissl (Fig.4). Ocasionalmente, os núcleos dos neurônios necróticos apresentavam aspecto vítreo. A necrose neuronal ocorreu tanto nos topos quanto nos sulcos das circunvoluções cerebrais. O edema na substância cinzenta era acentuado e, em alguns casos, deixava o neurópilo com aspecto esponjoso; ocorria separando a substância cinzenta da branca ou entre camadas de neurônios da substância cinzenta (Fig.5). Em seis casos, havia manguitos perivasculares focais ou multifocais leves de linfócitos e macrófagos e, em quatro outros bovinos, o infiltrado era constituído de neutrófilos e eosinófilos perivasculares e no 
neurópilo. Gliose focal ou difusa, congestão e hemorragias multifocais foram observadas com pouca frequência. Em nenhum caso foi observada neuronofagia e ou lesão residual (cicatriz). Lesões no tronco encefálico ocorreram em 12 casos (39\%), eram leves ou moderadas e restritas ao teto do mesencéfalo; caracterizavam-se por áreas geralmente simétricas e bilaterais de necrose neuronal focal, edema de neurópilo, tumefação de núcleos de células endoteliais, hemorragias ocasionais, esferóides axonais focais e raras células gitter. No tálamo, as alterações eram mais leves, focais, semelhantes às do mesencéfalo e ocorreram em oito casos, especialmente afetando os núcleos talâmicos ventrais póstero-lateral e póstero-medial. Treze bovinos apresentaram alterações de PEM nos núcleos basais; incluindo o núcleo caudado em seis casos e putame em cinco casos. Essas alterações foram semelhantes às encontradas no tálamo. Em sete casos, havia alterações semelhantes no hipocampo. Lesões hemorrágicas multifocais e perivasculares, leves ou moderadas, foram observadas no tálamo, núcleos basais e hipocampo. Poucos casos apresentaram alterações no cerebelo; em quatro bovinos havia hemorragias extensas afetando várias camadas do córtex cerebelar, em um caso havia necrose de neurônios da camada de

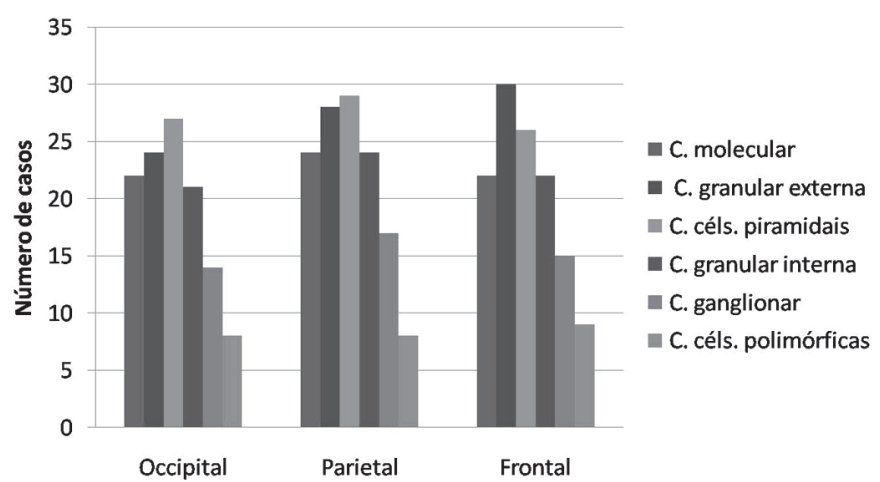

Fig.9. Distribuição de necrose neuronal (neurônios vermelhos) nas lâminas de neurônios do córtex occipital, parietal e frontal em 31 casos de polioencefalomacia em bovinos. $\mathrm{C}=$ camada; $\mathrm{C}$ céls. $=$ camada de células .

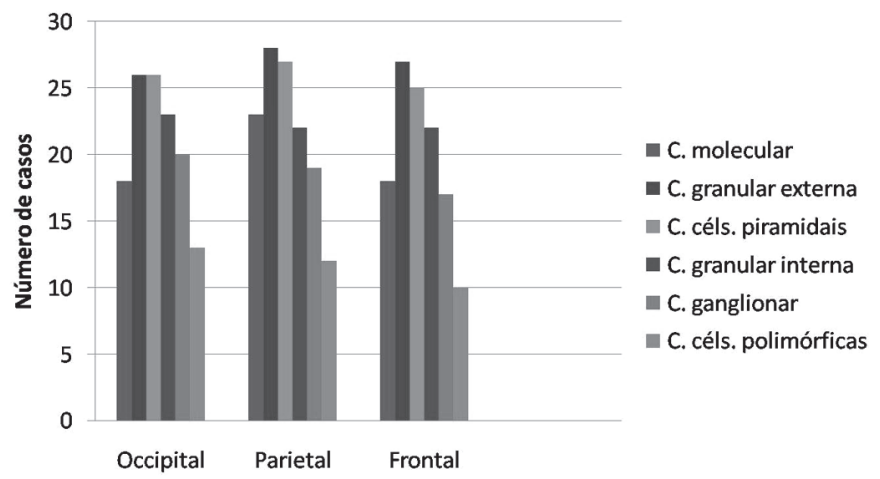

Fig.10. Distribuição de edema no córtex occipital, parietal e frontal em 31 casos de polioencefalomacia em bovinos. $C=$ camada; $\mathrm{C}$ céls. $=$ camada de células. células granulares e em outro ocorreu necrose multifocal dos neurônios de Golgi, que ocorrem em meio a camada de células granulares do cerebelo.

A distribuição da necrose neuronal nas lâminas de neurônios do córtex occipital, parietal e frontal está na Fig.9; as principais regiões afetadas foram as camadas de células piramidais, granular externa, molecular e granular interna. A distribuição do edema nas mesmas regiões está na Fig.10; o edema foi mais acentuado nas camadas granular externa, de células piramidais, granular interna, molecular e ganglionar. As camadas granular externa e interna foram as regiões mais afetadas tanto por neurônios necróticos como por edema em todas as regiões avaliadas.

\section{DISCUSSÃO}

Nos casos avaliados neste estudo a polioencefalomalacia (PEM) caracterizou-se por uma doença de evolução aguda (12 horas) ou subaguda (8 dias). No entanto casos crônicos (Gonçalves et al. 2001) e mesmo de recuperação (Nakazato et al. 2000, Riet-Correa et al. 2007, Vieira et al. 2007) de PEM têm sido descritos. Dados epidemiológicos semelhantes aos observados neste estudo foram mencionados por outros autores, indicando que a PEM pode ocorrer na forma de surtos (Moro et al. 1994, Nakazato et al. 2000) ou como casos isolados (Ferreira et al. 1986, Lemos 2005) e não apresenta sazonalidade (Nakazato et al. 2000, Lemos 2005). Os coeficientes de morbidade $(0,04 \%-6,66 \%)$, mortalidade $(0,04 \%-6,66 \%)$, e letalidade (50\%-100\%), observados neste estudo foram semelhantes aos relatados por outros autores que indicam que a morbidade e mortalidade podem variar de $1 \%$ 14\% (Nakazato et al. 2000, Lemos 2005) e a letalidade de $43 \%$ a $100 \%$ (Lemos 2005), dependendo da resposta ao tratamento.

Não houve preferência por raça ou sexo. O fato de um maior número de bovinos sem raça definida e Nelore ser afetado respectivamente no RS e Centro-Oeste, deve-se a essa raça ou mistura de raças predominarem nas duas populações estudadas. Fato semelhante ocorreu na descrição original de PEM (Jensen et al. 1956) em que 66,36\% dos bovinos afetados eram da Hereford, uma raça predominante nos confinamentos daquela região dos Estados Unidos. Os bovinos afetados por PEM no presente estudo dividiram-se igualmente entre machos e fêmeas.

Nos 13 casos de PEM diagnosticados no RS, dez bovinos eram oriundos da Região central do Estado, dois bovinos eram provenientes da região Oeste e um da Nordeste. É muito provável que esse fato se deva à proximidade do LPV/UFSM com as propriedades rurais da região Central e não a uma tendência de uma maior incidência em uma determinada região do Estado. PEM já foi diagnosticada em bovinos em outras regiões do RS, como a Central (Santos et al. 1983, Sanches et al. 2000), Sul (Riet-Correa et al. 1998, Motta et al. 1999, Schild et al. 2005), Campanha Meridional (Santos et al. 1983) e metropolitana de Porto Alegre (Traverso et al. 2001, Guagnini 
et al. 2005). Os casos de PEM do Mato Grosso do Sul (MS) descritos neste estudo ocorreram em maior número na região Central do estado, mas também em outras regiões como a Sul, Norte e no Pantanal. Dados semelhantes foram observados anteriormente (Purisco 1982, Nakazato et al. 2000, Lemos 2005). Os quatro casos de Mato Grosso (MT) ocorreram no Centro e Sudeste do estado e os dois casos de Goiás (GO) ocorreram nas regiões Central e Sudeste. Apenas um surto da enfermidade havia sido descrito anteriormente em MT, mas a região de ocorrência não foi mencionada (Grecco et al. 2001) e casos de PEM já foram relatados em bovinos na região central de Goiás (Miguel et al. 2005). Esses números, tanto do nosso estudo, quanto de estudos anteriores, ainda são demasiadamente exíguos para se prestarem a qualquer conclusão quanto à incidência geográfica, mas estudos nesse sentido deveriam ser incrementados em todo o país porque a maior ocorrência de casos em uma determinada região poderia estar associada a um fator (ou fatores) ambiental (por ex., excesso de enxofre na água, planta fixadora de enxofre) como já foi determinado em outros estudos nos Estados Unidos (Bulgin et al. 1996, Gould et al. 2002) e na Nova Zelândia (Hill \& Ebbett 1997).

Os casos de PEM diagnosticados no RS e no CentroOeste apresentam diferenças quanto à faixa etária dos animais afetados: a maioria dos casos diagnosticados no RS ocorreu em bovinos jovens (um ano de idade ou menos), enquanto no Centro-Oeste prevaleceram os casos em bovinos adultos. Em ambas as regiões estudadas, o principal sistema de criação foi o extensivo, com exceção de dois casos do RS os animais eram semi-confinados. Embora, em muitos países, casos de PEM ocorram esporadicamente em bovinos jovens confinados (Jensen et al. 1956, Harries 1987, Gooneratne et al. 1989, Niles et al. 2000, Radostits et al. 2007), no Brasil e no Uruguai os casos frequentemente são descritos em bovinos adultos criados extensivamente (Ferreira et al. 1986, Moro et al. 1994, Motta et al. 1999, Nakazato et al. 2000, Grecco et al. 2001, Miguel et al. 2005, Riet-Correa et al. 2007, Vieira et al., 2007), indicando que algum fator ou fatores diferentes participam da patogênese da doença nesses locais.

Surtos de PEM ocorrem após mudança brusca na alimentação de ruminantes quando da troca de pastagem ruim para outra de excelente qualidade, sem prévia adaptação da microbiota ruminal (Jensen et al. 1956, Moro et al. 1994). Isso pode ter ocorrido em três bovinos deste estudo que foram transferidos entre propriedades, dias antes de desenvolverem PEM; ocorrência semelhante havia sido observada em dois surtos da doença em bovinos no agreste de Pernambuco (Vieira et al. 2007). Em uma propriedade do Rio Grande do Sul, a doença ocorreu em animais em criação semi-intensiva, em condições de manejo semelhantes às descritas por outros autores como associadas à doença (Niles et al. 2000, Gonçalves et al. 2001, Traverso et al. 2001) e um outro bovino apresentou PEM após ter sido colocado em um pasto recentemente adubado com uréia. Não há informações na lite- ratura da relação da doença em bovinos com a intoxicação por uréia, embora encefalomalacia tenha sido descrita em suínos alimentados com ração com $15 \%$ de uréia (Radostits et al. 2007).

A doença ocorreu em praticamente todos os meses do ano nas duas regiões estudadas, não apresentando sazonalidade, semelhante ao observado por outros autores (Gabbedy \& Richards 1977, Nakazato et al. 2000, Vieira et al. 2007) No entanto, são descritos surtos de PEM em MS (Purisco 1982) especialmente no período de seca da região (junho a setembro), e a ocorrência dos casos é associada à ingestão de cadáveres e carência de pastagens. Na Turquia, 256 casos de PEM associada à ingestão de brotos de cevada, ricos em enxofre, foram observados em bovinos de corte e de leite nos meses de agosto, outubro e dezembro (Kul et al. 2006). Em 111 casos da doença descritos nos EUA (Jensen et al. 1956) dois tipos de sazonalidade foram descritos: bovinos criados intensivamente, eram afetados no inverno (janeiro) e bovinos criados extensivamente eram afetados no verão (julho).

No presente estudo, os baixos índices de morbidade e mortalidade e o alto índice de letalidade foram semelhantes aos observados em outros trabalhos de PEM em bovinos (Gooneratne et al. 1989, Riet-Correa et al. 1998, Motta et al. 1999, Nakazato et al. 2000, Traverso et al. 2001, Haydock 2003, Kul et al. 2006). Dos 20 casos onde foi possível determinar o índice de letalidade, em 14 esse índice foi de $100 \%$. Tanto nos casos do RS, quanto nos do Centro-Oeste, a doença foi observada na forma de surtos (15 casos) ou como casos isolados (8 casos). Em alguns relatos de PEM associados às intoxicações por enxofre (Dickie et al. 1979, Hamlem et al. 1993, Jeffrey et al. 1994, Hill \& Ebbett 1997) ou por sal com privação de água (Lindley 1977, Trueman \& Clague 1978), os índices de morbidade foram superiores aos do presente trabalho, demonstrando que a causa específica interfere na epidemiologia da doença.

Os sinais clínicos apresentados pelos bovinos deste estudo foram semelhantes aos relatados em outras descrições de PEM em bovinos (Nakazato et al. 2000, Gonçalves et al. 2001, Vieira et al. 2007). Em bovinos intoxicados por sal associado à privação de água no Uruguai, o quadro clínico incluiu sinais nervosos, cegueira, depressão e enoftalmia (Riet-Correa et al. 2007). Alguns bovinos do presente estudo apresentaram sinais nervosos causados por compressão do tronco encefálico, como nistagmo, ataxia, diminuição do tônus da língua e estrabismo e por compressão do cerebelo, como opistótono. Foram observados quadros clínicos agudos com duração de poucas horas até quadros subagudos com oito dias de duração; no entanto, o curso clínico da maioria dos casos variou de dois a quatro dias. Relatos da ocorrência de PEM em bovinos de São Paulo (Gonçalves et al. 2001), dão conta de um curso clínico mais longo, que variou de dois a 25 dias (média de 12 dias).

As alterações macroscópicas observadas no encéfalo 
dos bovinos afetados por PEM neste estudo foram muito semelhantes aos achados de outros autores (Jensen et al. 1956, Ferreira et al. 1986, Moro et al. 1994, Nakazato et al. 2000). Em onze casos não foram observadas lesões macroscópicas. Isso provavelmente está relacionado a casos com curso clínico agudo em que as lesões não se desenvolveram a ponto de serem observadas na macroscopia, ou se desenvolveram a um ponto que, embora possíveis de serem observadas, são facilmente negligenciáveis. Os achados de necropsia variam de acordo com a severidade e a duração do curso clínico (Lemos \& Riet-Correa 2007). Em caso onde as lesões macroscópicas são difíceis de discernir, o exame macroscópico sob aplicação pela lâmpada de Wood é recomendado (Jackman \& Edwin 1983). Em dois casos havia hemorragias no tronco encefálico e no cerebelo associadas à herniação do cerebelo pelo forame magno. Achados semelhantes foram encontrados em bovinos intoxicados por enxofre (Loneragan et al. 1998). Em outros casos de PEM, também associados à intoxicação por enxofre (Hamlem et al. 1993), hemorragias bilaterais e extensas envolviam núcleos basais, tálamo, mesencéfalo (colículos rostrais e caudais) e bulbo. Em ovinos, hemorragias são descritas com maior frequência e intensidade nas lesões de PEM causadas pela intoxicação por amprólio (Morgan 1974, Lemos 2008).

As alterações microscópicas são qualitativamente semelhantes às descritas em várias publicações anteriores (Jensen et al. 1956, Jeffrey et al. 1994, Nakazato et al. 2000, Barros et al. 2006, Riet-Correa et al. 2007). Em todos os casos, as alterações histológicas predominaram no córtex telencefálico, mas em alguns casos, lesões de menor intensidade foram também observadas no mesencéfalo, tálamo, núcleos basais, hipocampo e cerebelo. Lesões semelhantes às descritas aqui foram observadas em casos de PEM causada por intoxicação por enxofre (Hamlem et al. 1993, Jeffrey et al. 1994, Low et al. 1996, Loneragan et al. 1998). Em bovinos intoxicados naturalmente por enxofre, hemorragias focais no tálamo e mesencéfalo ocorreram secundárias a degeneração de veias e vênulas (Loneragan et al. 1998) e necrose fibrinóide de pequenas arteríolas foi descrita no tálamo (Hamlem et al. 1993) e mesencéfalo (Hamlem et al. 1993, Hill \& Ebbett 1997). Esse quadro é considerado uma forma mais grave da doença associada ao consumo excessivo de enxofre (Gould 2000). Alguns autores sugerem que nos casos de PEM em que há necrose neuronal cortical associada a lesões em estruturas mais ventrais do encéfalo, o quadro é sugestivo de toxicose por enxofre, permitindo a diferenciação da PEM relacionada à deficiência de tiamina (Jeffrey et al. 1994, Low et al. 1996). Levando esses dados em consideração, é possível que alguns dos casos descritos neste trabalho estejam associados à intoxicação por enxofre, embora essa hipótese não tenha sido confirmada laboratorialmente. Malacia no cerebelo, como a encontrada em casos deste estudo, ocorre em alguns casos de PEM, provavelmente em função de forças exercidas sobre o cerebelo durante a herniação pelo forame magno (Morgan 1974, Lima et al. 2005, Lemos \& Riet-Correa 2007).

A necrose neuronal e o edema (espongiose) foram mais acentuados nas camadas granular externa e interna do córtex occipital, parietal e frontal. Na PEM associada à intoxicação por enxofre em bovinos, a necrose predomina nas camadas corticais superiores e médias de neurônios piramidais (Hamlem et al. 1993, Jeffrey et al. 1994) e a espongiose ocorre especialmente nas camadas profundas (Gould 2000). Já em ovinos intoxicados experimentalmente por amprólio e naturalmente por enxofre, as lesões de PEM ocorrem homogeneamente entre as camadas de neurônios corticais (Morgan 1974, Bulgin et al. 1996, Low et al. 1996) ou afetam as camadas corticais mais profundas (Bulgin et al. 1996). No presente trabaIho, as alterações histológicas foram observadas tanto nos giros quanto nos sulcos. Essa distribuição já havia sido descrita em relação a PEM (Morgan 1974). Entretanto, em alguns casos de intoxicação por chumbo em bovinos, a necrose neuronal é descrita especificamente nos giros (Christian \& Tryphonas 1971, Krametter-Froetscher et al. 2007) e afetando principalmente o telencéfalo occipital (Christian \& Tryphonas 1971). Essa distribuição pode auxiliar no diagnóstico diferencial entre essas duas causas de PEM.

Astrócitos Alzheimer tipo II são classicamente encontrados no encéfalo em casos de encefalopatia hepática ou renal (Summers et al. 1995). Embora não seja um achado histológico comum nos casos de PEM, no presente trabalho, essas células foram observadas em alguns casos na substância cinzenta dos telencéfalos associadas à necrose neuronal e espongiose do neurópilo. $\mathrm{Na}$ encefalopatia hepática, os astrócitos Alzheimer tipo II formam-se em resposta à ação da amônia e de outras toxinas ao sistema nervoso central (Norenberg 1987). Na necrose neuronal, por não possuírem alguns receptores membrana-específicos, os astrócitos são mais resistentes que os neurônios aos efeitos deletérios da ação de neurotransmissores aminoácidos excitatórios (Farooqui \& Horrocks 1991). Assim, pode haver acúmulo astrocitário de ácido láctico e diminuição do pH intracelular, o que resulta em tumefação celular (Staub et al. 1990). Nenhuma patogênese foi ainda proposta até o momento para a formação dos astrócitos Alzheimer tipo II na PEM.

Em poucos casos havia leve infiltrado inflamatório perivascular de células mononucleares. Esse aspecto histológico da PEM estar associada à ausência de células inflamatórias ou a um infiltrado inflamatório leve é um achado importante no diagnóstico diferencial entre as formas não-infecciosas de PEM e PEM causada pela infecção pelo herpesvírus bovino (BoHV), uma vez que nas duas enfermidades ocorrem lesões macro e microscópicas semelhantes e que na infecção por BoHV a inflamação geralmente é moderada ou acentuada, especialmente nos lobos frontais (Rissi et al. 2006, Rissi et al. 2008). No presente trabalho, infiltrados leves de neutrófilos e eosinófi- 
los foram encontrados em alguns casos. A presença de eosinófilos no espaço perivascular é bem caracterizada na intoxicação por sal em suínos (Summers et al. 1995). Em outras espécies, essa célula tem sido observada esporadicamente, como na intoxicação por chumbo em bovinos (Christian \& Tryphonas 1971). Porém, em descrições de intoxicação por sal em bovinos e ovinos, não há infiltrado de eosinófilos nas lesões de PEM (Trueman \& Clague 1978, Scarratt et al. 1985). Alterações histológicas avançadas de PEM como neuronofagia e lesão residual não foram observadas no presente trabalho. No entanto, essas lesões são descritas com frequência associada à infecção por BoHV em bovinos (Rissi et al. 2006, Rissi et al. 2008).

\section{REFERÊNCIAS}

Anderton N., Cockrum P.A., Walker D.W. \& Edgar J.A. 1994. Identification of a toxin suspected of causing death in livestock grazing Phalaris pastures, p.269-274. In: Colegate S.M. \& Dorling P.R. (Eds), Plant-Associated Toxins: Agricultural, phytochemical and ecological aspects. CAB International, Farnham Royal, Slough, UK. 596p.

Barros C.S.L., Driemeier D., Dutra I.S. \& Lemos R.A.A. 2006. Doenças do Sistema Nervoso de Bovinos no Brasil. Agnes, São Paulo, p.166-171.

Bulgin M.S., Lincoln S.D. \& Mather G. 1996. Elemental sulfur toxicosis in a flock of sheep. J. Am. Vet. Med. Assoc. 208:1063-1065.

Carrillo B.J., Ambrogí A., Schudel A.A., Vazquez M., Dahme E. \& Pospischil A. 1983a. Meningoencephalitis caused by IBR virus in calves in Argentina. Zentralbl. Veterinärmed. Reihe B 30:327-332.

Carrillo B.J., Pospischil A. \& Dahme E. 1983b. Pathology of a bovine necrotizing encephalitis in Argentina. Zentralbl. Veterinärmed. Reihe B 30:161-168.

Christian R.G. \& Tryphonas L. 1971. Lead poisoning in cattle: Brain lesions and hematologic changes. Am. J. Vet. Res. 32:203-216.

Colodel E.M., Loretti A.P., Cruz C.E.F. \& Driemeier D. 1998. Polioencefalomalacia em caprinos associada à ingestão dos frutos de Hovenia dulcis ("uva-do-japão"). Boletim do Laboratório Regional de Diagnóstico, Pelotas, 25:35-42.

David N., Hübner S.O., Riet-Correa F., Halfen D. \& Lemos R.A.A. 2007. Reactivation of latent bovine herpesvirus type 5 in cattle with polioencephalomalacia induced by ammonium sulphate. Pesq. Vet. Bras. 27:435-441.

Dickie C.W., Nelson R.J., Frazee D.G., Krugman L.D. \& Bronner E. 1979. Polioencephalomalacia in range cattle. J. Am. Vet. Med. Assoc. 175:460-462.

Edwin E.E., Markson L.M., Shreeve J., Jackman R. \& Carrol P.J. 1979. Diagnostic aspects of cerebrocortical necrosis. Vet. Rec. 104:4-8.

Farooqui A.A. \& Horrocks L.A. 1991. Excitatory amino acid receptors, neural membrane phospholipid metabolism and neurological disorders. Brain Res. Rev. 16:171-191.

Ferreira F.A., Coelho H.E. \& Bastos J.E.D. 1986. Polioencefalomalácia em bovinos no estado de Minas Gerais. Arq. Bras. Med. Vet. Zootec. 38:693-700.

Gabbedy B.J. \& Richards R.B. 1977. Polioencephalomalacia of sheep and cattle. Aust. Vet. J. 53:37-38.

Gonçalves R.C., Viana L., Sequeira J.L., Bandarra E.P., Chiacchio S.B. \& Kuchembuck M.R.G. 2001. Aspectos clínicos, anatomopatológicos e epidemiológicos da polioencefalomalácia em bovinos, na região de Botucatu, SP. Veterinária Notícias 7:53-57.

Gooneratne S.R., Olkowski A.A., Klemmer R.G., Kessler G.A. \& Christensen D.A. 1989. High sulfur related thiamine deficiency in cattle: a field study. Can. Vet. J. 30:139-146.
Gould D.H. 1998. Polioencephalomalacia. J. Anim. Sci. 76:309-314.

Gould D.H. 2000. Update on sulfur-related polioencephalomalacia. Vet. Clin. North Am., Food Anim.Pract. 16:481-496.

Gould D.H., Dargatz D.A., Garry F.B., Hamar D.W. \& Ross P.F. 2002. Potentially hazardous sulfur conditions on beef cattle ranches in the United States. J. Am. Vet. Med. Assoc. 221:673-677.

Grecco F.B., Schein F. \& Dantas A.F.M. 2001. Polioencefalomalacia em bovinos no Estado de Mato Grosso. 10ํㅡㄹ Enave, Pirassununga, p.121. (Resumo)

Guagnini F.S., Raymundo D.L., Borba M.R., Bandarra P.M., Leal J.S., Pedroso P.M.O., Seitz A.L., Colodel E.M. \& Driemeier D. 2005. Diagnósticos de doenças do sistema nervoso central de bovinos, a partir da vigilância sanitária da encefalopatia espongiforme transmissível no período de 2002 a 2004. Arq. Bras. Med. Vet. Zootec. 57(Supl.1):73.

Guimarães E.B., Lemos R.A.A., Nogueira A.P.A. \& Souza A.C. 2008. Ocorrência natural de polioencefalomalacia em búfalos Murrah (Buballis bubalis), mantidos em pastagem de gramínea consorciada com leguminosa em fase de rebrota, em MS. Encontro Nacional de Diagnóstico Veterinário, Campo Grande, MS, p.227-228.

Hamlen H., Clark E. \& Janzen E. 1993. Polioencephalomalacia in cattle consuming water with elevated sodium sulfate levels: A herd investigation. Can. Vet. J. 34:153-158.

Harries N. 1987. Polioencephalomalacia in feedlot cattle drinking water high in sodium sulfate. Can. Vet. J. 28:717.

Haydock D. 2003. Sulfur-induced polioencephalomalacia in a herd of rotationally grazed beef cattle. Can. Vet. J. 44:828-829.

Hill F.I. \& Ebbett P.C. 1997. Polioencephalomalacia in cattle in New Zealand fed chou moellier (Brassica oleracea). New Zealand Vet. J. 45:37-39.

Innes J.R.M. \& Saunders L.Z. 1962. Encephalomalacia and myelomalacia, p.607-609. In: Ibid. (Eds), Comparative Neuropathology. Academic Press, New York. 839p.

Jackman R. \& Edwin E.E. 1983. Cerebral autofluorescence and thiaminase deficiency in cerebrocortical necrosis. Vet. Rec. 112:548550.

Jeffrey M., Duff J.P., Higgins R.J., Simpson V.R., Jackman R., Jones T.O., Mechie S.C. \& Liversey C.T. 1994. Polioencephalomalacia associated with the ingestion of ammonium sulphate by sheep and cattle. Vet. Rec. 134:343-348.

Jensen R., Griner L.A. \& Adams O.R. 1956. Polioencephalomalacia of cattle and sheep. J. Am. Vet. Med. Assoc. 129:311-321.

Krametter-Froetscher R., Tataruch F., Hauser S., Leschnik M., Url A. \& Baumgartner W. 2007. Toxic effects seen in a herd of beef cattle following exposure to ash residues contaminated by lead and mercury. Vet. J. 174:99-105.

Kul O., Karahan S., Basalan M. \& Kabakci N. 2006. Polioencephalomalacia in cattle: A consequence of prolonged feeding barley malt sprouts. J. Vet. Med. A 53:123-128.

Lemos R.A.A. \& Riet-Correa F. 2007. Polioencefalomalacia, p.658-670. In: Riet-Correa F., Schild A.L., Lemos R.A.A. \& Borges J.R.J. (Eds), Doenças de Ruminantes e Eqüídeos. Vol.2. $3^{\mathrm{a}}$ ed. Pallotti, Santa Maria. $695 p$.

Lemos R.A.A. 2005. Enfermidades do sistema nervoso de bovinos de corte das regiões Centro-Oeste e Sudeste do Brasil. Tese de Doutorado, Universidade Estadual Paulista, Jaboticabal, SP. 150p.

Lemos R.A.A. 2008. Comunicação pessoal (Universidade Federal do Mato Grosso do Sul, Campo Grande).

Lemos R.A.A., Driemeier D., Guimarães E.B., Dutra I.S., Mori A.E. \& Barros C.S.L. 2004. Lead poisoning in cattle grazing pasture contaminated by industrial waste. Vet. Human Toxicol. 46:326-328.

Lima E.F., Riet-Correa F., Tabosa I.M., Dantas A.F.M., Medeiros J.M. \& Sucupira Júnior G. 2005. Polioencefalomalacia em caprinos e ovinos na região semi-árida do Nordeste do Brasil. Pesq. Vet. Bras. 25:9-14. 
Lindley W.H. 1977. Water deprivation in cattle. J. Am. Vet. Med. Assoc. 171:439-440.

Linklater K.A., Dyson D.A. \& Morgan K.T. 1977. Faecal thiaminase in clinically normal sheep associated with outbreaks of polioencephalomalacia. Res. Vet. Sci. 22:308-312.

Loew F.M. \& Dunlop R.H. 1972. Induction of thiamine inadequacy and polioencephalomalacia in adult sheep with amprolium. Am. J. Vet. Res. 33:2195-2205.

Loneragan G.H., Gould D.H., Callan R.J., Sigurdson C.J. \& Hamar D.W. 1998. Association of excess sulfur intake and an increase in hydrogen sulfide concentrations in the ruminal gas cap of recently weaned beef calves with polioencephalomalacia. J. Am. Vet. Med. Assoc. 213:15991604.

Low J.C., Scott P.R., Howie F., Lewis M., FitzSimons J. \& Spence J.A. 1996. Sulphur-induced polioencephalomalacia in lambs. Vet. Rec. 138:327-329.

Markson L.M., Lewis G., Terlecki S., Edwin E.E. \& Ford J.E. 1972. The aetiology of cerebrocortical necrosis: The effects of administering antimetabolites of thiamine to preruminant calves. Brit. Vet. J. 128:488499.

Markson L.M., Edwin E.E., Lewis G. \& Richardson C. 1974. The production of cerebrocortical necrosis in ruminant calves by the intraruminal administration of amprolium. Brit. Vet. J. 130:9-16.

Mella C.M., Perez-Oliva O. \& Loew F.M. 1976. Induction of bovine polioencephalomalacia with a feeding system based on molasses and urea. Can. J. Comp. Med. 40:104-110.

Miguel M.P., Souza M.A., Brum K.B., Jorge P.H.C., Porto R.R.N.G. \& Brito L.A.B. 2005. Freqüência de casos de polioencefalomalacia em bovinos encaminhados ao Setor de Patologia Animal da Escola de Veterinária da Universidade Federal de Goiás - UFG no período de jan/2003 a mar/2005. Arq. Bras. Med. Vet. Zootec. 57(Supl.1):72.

Morgan K.T. 1974. Amprolium poisoning of preruminant lambs: An ultrastructural study of the cerebral malacia and the nature of the inflammatory response. J. Path. 112:229-236.

Moro L., Nogueira R.H.G., Carvalho A.U. \& Marques D.C. 1994. Relato de três casos de polioencefalomalacia em bovinos. Arq. Bras. Med. Vet. Zootec. 46:409-416.

Motta A., Raffi M.B., Grecco F., Stigger A.L. \& Raposo J.B. 1999. Poliencefalomalácia em bovinos. 9ํㅡㄹ Enave, Belo Horizonte, p.50. (Resumo)

Nakazato L., Lemos R.A.A. \& Riet-Correa F. 2000. Polioencefalomalacia em bovinos nos estados de Mato Grosso do Sul e São Paulo. Pesq. Vet. Bras. 20:119-125.

Nascimento I.A., Afonso J.A.B., Tokarnia C.H., Mendonça C.L., Costa N.A., Souza M.I., Oliveira L.G.L., Vieira A.C.S. \& Pereira A.L.P. 2003. Polioencefalomalacia em ovinos: Relato de caso. $V$ Congresso Pernambucano de Medicina Veterinária, Recife, PE.

Niles G.A., Morgan S.E. \& Edwards W.C. 2000. Sulfur-induced polioencephalomalacia in stocker calves. Vet. Human Toxicol. 42:290-291.

Norenberg M.D. 1987. The role of astrocytes in hepatic encephalopathy. Neurochem. Pathol. 6:13-33.

Priester W.A. \& Hayes H.M. 1974. Lead poisoning in cattle, horses, cats, and dogs as reported by all Colleges of Veterinary Medicine in the United States and Canada from July 1968, through June 1972. Am. J. Vet. Res. 35:567-569.
Pritchard D. \& Eggleston G.W. 1978. Nardoo fern and polioencephalomalacia. Aust. Vet. J. 54:204-205.

Purisco E. 1982. Ocorrência de polioencefalomalácia em bovinos no Estado de Mato Grosso do Sul. Monografia. Universidade Federal de Mato Grosso do Sul, Campo Grande, MS. 24p.

Radostits O.M., Gay C.C., Hinchcliff K.W. \& Constable P.D. 2007. Veterinary Medicine: A textbook of the diseases of cattle, horses, sheep, pigs, and goats. $10^{\text {th }}$ ed. Saunders Elsevier, Edinburgh, p.20062012.

Ramos J.J., Ferrer L.M., García L., Fernández A. \& Loste A. 2005. Polioencephalomalacia in adult sheep grazing pastures with prostate pigweed. Can. Vet. J. 46:59-61.

Riet-Correa F., Ferreira J.L.M., Schild A.L. \& Méndez M.C. 1998. Polioencefalomalacia em bovinos. Boletim do Laboratório Regional de Diagnóstico, Pelotas, 18:19-21.

Riet-Correa F., Rivero R., Dutra F., Lemos R.A.A. \& Easton C. 2007. Polioencephalomalacia. 35a Jornadas Uruguayas de Buiatría, p.191198.

Rissi D.R., Oliveira F.N., Rech R.R., Pierezan F., Lemos R.A.A. \& Barros C.S.L. 2006. Epidemiologia, sinais clínicos e distribuição das lesões encefálicas em bovinos afetados por meningoencefalite por herpesvírus bovino-5. Pesq. Vet. Bras. 26:123-132.

Rissi D.R., Pierezan F., Silva M.S., Flores E.F. \& Barros C.S.L. 2008. Neurological disease in cattle in southern Brazil associated with Bovine herpesvirus infection. J. Vet. Diagn. Invest. 20:346-349.

Sanches A.W.D., Langohr I.M., Stigger A.L. \& Barros C.S.L. 2000. Doenças do sistema nervoso central em bovinos no Sul do Brasil. Pesq. Vet. Bras. 20:113-118.

Santos M.N., Jardim Filho J.O. \& Grando F.A. 1983. Polioencefalomálacia em bovinos no Rio Grande do Sul. Pesq. Vet. Bras. 3:37-39.

Scarratt W.K., Collins T.J. \& Sponenberg D.P. 1985. Water deprivationsodium chloride intoxication in a group of feeder lambs. J. Am. Vet. Med. Assoc. 186:977-978.

Schild A.L., Ferreira J.L.M. \& Soares M.P. 2005. Polioencefalomalácia em bovinos. Boletim do Laboratório Regional de Diagnóstico, Pelotas, 25:32-34.

Staub F., Baethmann A., Peters J., Weigt H. \& Kempski O. 1990. Effects of lactacidosis on glial cell volume and viability. J. Cereb. Blood Flow Metab. 10:866-876.

Summers B.A., Cummings J.F. \& De Lahunta A. 1995. Veterinary Neuropathology, Mosby, St Louis. 527p.

Traverso S.D., Colodel E.M., Loretti A.P., Seitz A.L., Correa A.M., Krauspenhar C. \& Driemeier D. 2001. Polioencefalomalácia em bovinos leiteiros no Rio Grande do Sul suplementados com enxofre. 10응 Enapave, Pirassununga, p.72. (Resumo)

Traverso S.D., Loretti A.P., Donini M.A. \& Driemeier D. 2004. Lead poisoning in cattle in southern Brazil. Arq. Bras. Med. Vet. Zootec. 56:418-421.

Trueman K.F. \& Clague D.C. 1978. Sodium chloride poisoning in cattle. Aust. Vet. J. 54:89-91.

Vieira A.C.S., Afonso J.A.B., Tokarnia C.H., Costa N.A., Mendonça C.L. \& Souza M.I. 2007. Estudo epidemiológico, clínico e patológico em ruminantes com polioencefalomalácia no agreste meridional de Pernambuco. Revta Bras. Med. Vet. 29:65-68. 